\title{
Genetic Distances of Crucian Carp Populations analyzed by PCR Approach
}

\author{
Jun-Hyub Jeon and ${ }^{\dagger} J o n g-M a n$ Yoon \\ Dept. of Aquatic Life Medicine, College of Ocean Science and Technology, Kunsan National University, \\ Gunsan 54150, Korea
}

\begin{abstract}
Genomic DNAs isolated from crucian carp of four rivers, belonging to the family Cyprinidae was amplified by seven oligonucleotides primers. In the present study, we employed hierarchical clustering method in order to reveal genetic distances and variations. Crucian carp was acquired from Hangang river (CAH), Geumgang river (CAG), Nakdonggang river (CAN) and Yeongsangang river (CAY). The primer BION-12 generated the most loci (a total of 50) with an average of 10 in the CAY population. The primer BION-10 generated the least loci (a total of 19), with an average of 3.8 in the CAG population, in comparison to the other primers used. Seven oligonucleotides primers made 16.7 average no. per primer of specific loci in the CAH population, 7.4 in the CAG population, 8.6 in the CAN population and 0.9 in the CAY population, respectively. The specific loci generated by oligonucleotides primers revealed inter-individual-specific characteristics, thus disclosing DNA polymorphisms. The dendrogram obtained by the seven oligonucleotides primers indicates four genetic clusters. The genetic distance that displayed significant molecular differences was between individuals no.06 and no.08 from the CAG population (genetic distance $=0.036$ ), while the genetic distance among the five individuals that displayed significant molecular differences was between individuals no.08 and no.09 from the CAG population (genetic distance $=$ 0.088). With regard to average bandsharing value (BS) results, individuals from CAY population $(0.985 \pm 0.009)$ exhibited higher bandsharing values than did individuals from $\mathrm{CAH}$ population $(0.779 \pm 0.049)(P<0.05)$. Relatively, individuals of CAY population were fairly closely related to that of CAN location (genetic distance between two populations $<0.016$ ).

Key words : Genetic distance, Crucian carp, Cyprinidae, Geumgang river, Hangang river, Hierarchical dendrogram, Nakdonggang river, Specific loci, Yeongsangang river
\end{abstract}

\section{INTRODUCTION}

Carassius auratus is, ecologically warm-water teleost species, belonging to class Actinopterygii, family Cyprinidae, widely inhabited the lakes, brooks, rivers and marshes under the natural ecosystem throughout the northeastern Asia region in countries in China, Taiwan, Japan and Korea (Kim \& Kang, 1993; Choi et al., 2002). The dorsal body color is yellowish brown and belly is a silvery-white tinged with brown. They have slightly long and flat to side body, a broad width of the caudal peduncle. As omnivores, they mainly eat a variety of feed/preys, such as aquatic insects, sessile diatoms, microscopic algae, debris, water plant and plankton. Crucian carp is ranked highest among the freshwater fishes in Korea as a game fish attracting millions of anglers owing to the quake of fingertips. In spite of the economic and scientific significance, the individuals of this fish species have decreased significantly owing mainly to impru-

\footnotetext{
Manuscript received May 05, 2016, Received in revised form May 11, 2016, Accepted May 25, 2016

${ }^{\dagger}$ Corresponding Author : Jong-Man Yoon, Dept. of Aquatic Life Medicine, College of Ocean Science and Technology, Kunsan National University, Gunsan 54150, Korea. Tel. : +82-63-469-1887, E-mail: jmyoon@kunsan.ac.kr

This is an Open Access article distributed under the terms of the Creative Commons Attribution Non-Commercial License (http:// creativecommons.org/licenses/by-nc/3.0) which permits unrestricted non-commercial use, distribution, and reproduction in any medium, provided the original work is properly cited.
} 
dent development, reckless fishing and predation of introduced species during the last three decades. However, these kinds of crucian carp, which are recognized important morphometrically (Panicz et al., 2011), ecologically (Jo et al., 2011) as well as biochemically (Johnston \& Maitland, 1980; Kim, 2015), are not molecular-biologically much researched like other finfishes. Only a few of information is known about the genetics of crucian carp in Korea (Yoon \& Park, 2001; Hong et al., 2007). In general, there are marked differences of the size, color and body structure in common carp along with the environmental surroundings of habitat such as water temperature, feed, stress and nutrition, etc (Oh \& Yoon 2014; Yoon 2015). We perform a clustering analysis to elucidate the genetic distances among four crucian carp populations from Hangang river, Geumgang river, Nakdonggang river and Yeongsangang river of the Korean Peninsula. Therefore, in this study, DNAs isolated from four crucian carp populations were analyzed by seven oligonucleotides primers with the aim of ascertaining the genetic distances by investigating their genetic similarity and diversity.

\section{MATERIALS AND METHODS}

1. Sampling, extraction of genomic DNA, PCR amplifycation conditions and data analysis

Crucian carp ranged in size from 40 to $100 \mathrm{~g}$ (average $70 \mathrm{~g}$ ) in body weight. The muscle obtained was frozen at $-18^{\circ} \mathrm{C}$ until use. Muscle tissues were collected separately from Carassius auratus of a site of Hangang river (CAH), a site of Geumgang river (CAG), a site of Nakdonggang river (CAN) and a site of Yeongsangang river (CAY) of the Korean Peninsula, respectively. PCR analysis was performed on DNA samples extracted from a total of 20 individuals using seven oligonucleotides primers (Yoon \& Park, 2006). DNA extraction was carried out according to the separation and extraction methods (Song \& Yoon, 2013). After several washings, lysis buffer I $\left(155 \mathrm{mM} \mathrm{NH}_{4} \mathrm{Cl} ; 10 \mathrm{mM}\right.$
$\mathrm{KHCO}_{3} ; 1 \mathrm{mM}$ EDTA) was added to the samples, and the mixture tubes were lightly inverted. Ice-cold $70 \%$ ethanol was added, and then the samples were centrifuged at $19,621 \mathrm{~g}$ for 5 minutes to extract the DNA from the lysates. The concentration of the extracted genomic DNA was measured with the absorbance ratio at $260 \mathrm{~nm}$ by a spectrophotometer (Beckman Coulter, Buckinghamshire, UK). The DNA pellets were incubation-dried for $2 \mathrm{hrs,}$ held at $-40^{\circ} \mathrm{C}$ until analysis and then dissolved in the TE buffer (10 mM Tris-HCl, pH 8.0; 1 mM EDTA). The amplification reaction was undertaken in a $20 \mu \mathrm{L}$ volume of reaction tube containing $10 \mathrm{ng}$ of template DNA, $20 \mu \mathrm{L}$ AccuPower premix (Bioneer Corp., Daejeon, Korea) and 1.0 unit primer (Bioneer Corp., Daejeon, Korea). Amplification products were separated by electrophoresis in $1.4 \%$ agarose gels (Bioneer Corp., Daejeon, Korea) with TBE (0.09 M Tris, $\mathrm{pH}$ 8.5; 0.09 M borate; 2.5 mM EDTA), using 100 bp DNA ladder (Bioneer Corp., Daejeon, Korea) as DNA molecular weight marker and detected by staining with EtBr. All of these oligonucleotides primers had $\mathrm{G}+\mathrm{C}$ content in the range 60-70\%. Seven oligonucleotides primers, BION-02 (5'CAATCGCCGT-3'), BION-03 (5'-AGGGGTCTTG-3'), BION-09 (5'-GGGTAACGCC-3'), BION-10 (5'-CTGAG ACGGA-3'), BION-12 (5'-TACAACGAGG-3'), BION14 (5'-TGGATTGGTC-3') and BION-19 (5'-GTCCACA CGG-3') were used to produce the unique shared loci to each population and shared loci by the four populations of Carassius auratus which could be counted. PCR was carried out using Programmable DNA Thermal Cycler (MJ Research Inc., Waltham, MA, USA). Similarity matrix containing bandsharing values (BS) between different individuals in Carassius auratus was calculated along with the procedures of Jeffreys \& Morton (1987) and Yoke-Kqueen \& Radu (2006). A hierarchical clustering tree was constructed using similarity matrices to produce a dendrogram, using the Systat version 10 (SPSS Inc., Chicago, IL, USA). 


\section{RESULTS AND DISCUSSION}

Genomic DNAs isolated from Carassius auratus obtained in Hangang river (CAH), Geumgang river (CAG), Nakdonggang river (CAN) and Yeongsangang river (CAY) were amplified at several times by PCR reactions. The amplified products were separated by agarose gel electrophoresis (AGE) with oligonucleotide primers and detected by staining with ethidium bromide. The hardship of the banding patterns was diverse between the primers and four populations (Fig. 1). Consequently, in the present study, the size of the DNA fragments, ranged from 150 to 2,000 bp. The higher fragment sizes $(>1,000 \mathrm{bp})$ are much more observed in the CAN population, as shown in Fig. 1. The bandsharing value between individuals no. 11 and no. 12 was 0.998 , which was the highest value identified within the CAN population. The seven oligonucleotides primers produced 16.7 average no. per primer specific to the $\mathrm{CAH}$ population, 7.4 in the CAG population, 8.6 in the CAN population and 0.9 in the CAY population, respectively, as

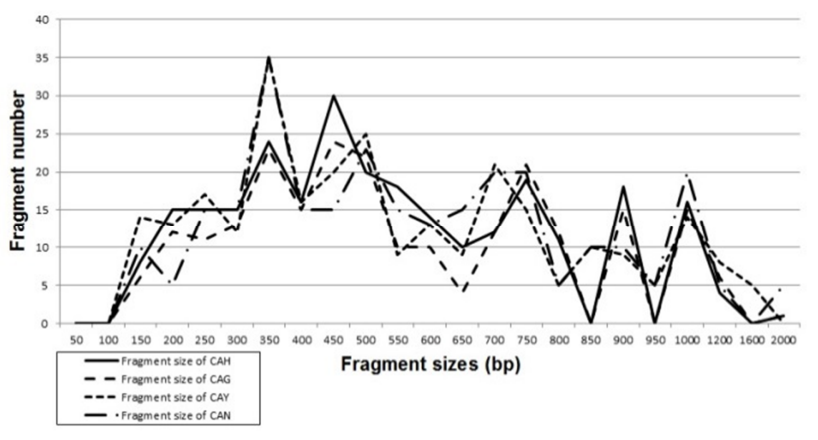

Fig. 1. Distribution of fragment sizes of Korean crucian carp from Hangang river (CAH), Geumgang river (CAG), Nakdonggang river (CAN) and Yeongsangang river (CAY). Solid lines: CAH. Long dotted lines: CAG. Short dotted lines: CAY. Solid/ dotted lines: CAN. The fragment numbers in each size interval have been computed from the pooled fragments obtained with all the primers. The higher fragment sizes $(>1,000 \mathrm{bp})$ are much more observed in the CAN population. illustrated in Table 1. The primer BION-12 generated the most loci (a total of 50) with then average of 10 in the CAY population. The primer BION-19 generated the most loci (a total of 43) with the average of 8.6 in the CAG population. The oligonucleotides primer BION-10 generated the least loci (a total of 19), with the average of 3.8 in the CAG population, in comparison to the other primers used. Six specific loci, with the average of 39.4 per primer, were identified in the CAY population. Fifty two specific loci, with the average of 33.1 per primer, were identified in the CAG population, as demonstrated in Table 1. The specific loci generated by oligonucleotides primers revealed interindividual-specific characteristics, thus disclosing DNA polymorphisms. Many researchers studied the sizes of DNA fragments in the PCR profiles of crucian carp (Carassius auratus) methods (Yoon \& Park, 2006; Takada et al, 2010) and Japanese crucian carp (Carassius cuvieri ) (Hong et al., 2007). Here, the seven oligonucleotide primers were used to generate the unique shared loci to each population and shared loci by the four populations. Especially, 420 numbers of shared loci by the four populations, with an average of 60 per primer, were observed among the four populations, as illustrated in Table 2. Interestingly, the primer BION-19 detected 100 shared loci by the four populations, major and/or minor fragments of sizes, which were identical in almost all of the samples. Especially, the oligonucleotides primer BION-02 generated 5 unique loci to each population, which were identifying each population in the $\mathrm{CAH}$ population. Also, the oligonucleotides primer BION-12 generated 50 unique loci to each population in the CAY population. Concerning average bandsharing value (BS) results, individuals from CAY population $(0.985 \pm 0.009)$ exhibited higher bandsharing values than did individuals from $\mathrm{CAH}$ population $(0.779 \pm 0.049)(P<0.05)$, as illustrated in Table 3 . In the present study, the dendrogram obtained by the seven oligonucleotides primers indicates four genetic clusters: cluster 1 (HANGANG01 HANGANG05), cluster 
Table 1. The number of average loci per lane, specific loci by PCR analysis using seven oligonucleotides primers in CAH, CAG, CAN and CAY population of the Korean Peninsula

\begin{tabular}{|c|c|c|c|c|c|c|c|c|}
\hline \multirow{2}{*}{ Primer } & \multicolumn{4}{|c|}{ No. of average loci per lane } & \multicolumn{4}{|c|}{ No. of specific loci } \\
\hline & $\mathrm{CAH}$ & $\mathrm{CAG}$ & CAN & CAY & $\mathrm{CAH}$ & $\mathrm{CAG}$ & CAN & CAY \\
\hline BION-02 & $5.8(29)$ & $6.8(34)$ & $6(30)$ & $7.6(38)$ & 24 & 9 & 15 & 3 \\
\hline BION-03 & $9.6(48)$ & $8.6(43)$ & $9(45)$ & $9(45)$ & 18 & 8 & 10 & 0 \\
\hline BION-09 & $7.2(36)$ & $5.2(26)$ & $6.6(33)$ & $6.6(33)$ & 21 & 6 & 8 & 3 \\
\hline BION-10 & $6.4(32)$ & $3.8(19)$ & $8.4(42)$ & $7(35)$ & 12 & 4 & 7 & 0 \\
\hline BION-12 & $6.2(31)$ & $6(30)$ & $9(45)$ & $10(50)$ & 16 & 10 & 5 & 0 \\
\hline BION-14 & $9.2(46)$ & $7.4(37)$ & $7.4(37)$ & $8(40)$ & 21 & 7 & 12 & 0 \\
\hline BION-19 & $8(40)$ & $8.6(43)$ & $8.6(43)$ & $7(35)$ & 5 & 8 & 3 & 0 \\
\hline $\begin{array}{l}\text { Average no. } \\
\text { per primer }\end{array}$ & $37.4(262)$ & $33.1(232)$ & $39.3(275)$ & $39.4(276)$ & $16.7(117)$ & $7.4(52)$ & $8.6(60)$ & $0.9(6)$ \\
\hline
\end{tabular}

The total number of loci generated by seven oligonucleotides primer in CAH, CAG, CAN and CAY population is shown in parentheses.

Table 2. The number of unique loci to each population and number of shared loci by the four populations generated by PCR analysis using seven oligonucleotides primers in CAH, CAG, CAN and CAY population, respectively

\begin{tabular}{|c|c|c|c|c|c|}
\hline \multirow[b]{2}{*}{$\begin{array}{l}\text { Primer } \backslash \\
\text { population }\end{array}$} & \multicolumn{4}{|c|}{$\begin{array}{l}\text { No. of unique loci } \\
\text { to each population }\end{array}$} & \multirow{2}{*}{$\begin{array}{c}\begin{array}{c}\text { No. of shared loci by } \\
\text { the four populations }\end{array} \\
\text { Four populations } \\
\text { (5 individuals per population) }\end{array}$} \\
\hline & $\mathrm{CAH}$ & CAG & CAN & CAY & \\
\hline BION - 02 & 5 & 25 & 15 & 35 & 20 \\
\hline BION - 03 & 30 & 35 & 35 & 45 & 60 \\
\hline BION - 09 & 15 & 20 & 25 & 30 & 40 \\
\hline BION - 10 & 20 & 15 & 35 & 35 & 60 \\
\hline BION - 12 & 15 & 20 & 40 & 50 & 60 \\
\hline BION - 14 & 25 & 30 & 25 & 40 & 80 \\
\hline BION - 19 & 35 & 35 & 40 & 35 & 100 \\
\hline Total no. & 145 & 180 & 215 & 270 & 420 \\
\hline $\begin{array}{l}\text { Average no. per } \\
\text { primer }\end{array}$ & 20.7 & 25.7 & 30.7 & 38.6 & 60 \\
\hline
\end{tabular}

2 (GEUMGANG06 GEUMGANG10), cluster 3 (NAK DONG11 NAKDONG15) and cluster 4 (YEONGSAN16 $\sim$ YEONGSAN20), as shown in Fig. 2. The shortest genetic distance that displayed significant molecular differences was between individuals no. 16 and no. 18 from the CAY population (genetic distance $=0.002$ ), while the longest genetic distance among the twenty individuals that displayed significant genetic differences was between individuals no. 03 and no. 05 from the CAH population (genetic distance $=0.377)$. The genetic distance that exhibited significant molecular differences was between individuals no.06 and no.08 from the CAG population (genetic distance $=0.036$ ), while the genetic distance among the five individuals that exhibited significant molecular differences was between 
Table 3. Multiple comparisons of average bandsharing values (mean \pm SD) among Korean crucian carp from Hangang river (CAH), Geumgang river (CAG), Nakdonggang river (CAN) and Yeongsangang river (CAY) were generated according to the bandsharing values and similarity matrix

\begin{tabular}{ccccc}
\hline \hline Population & CAH & CAG & CAN & CAY \\
\hline CAH & $0.779 \pm 0.049^{\mathrm{d}}$ & $0.739 \pm 0.040^{\mathrm{c}}$ & $0.632 \pm 0.021^{\mathrm{a}}$ & $0.645 \pm 0.024^{\mathrm{a}}$ \\
CAG & - & $0.851 \pm 0.037^{\mathrm{f}}$ & $0.650 \pm 0.033^{\mathrm{a}}$ & $0.682 \pm 0.018^{\mathrm{b}}$ \\
CAN & - & - & $0.887 \pm 0.079^{\mathrm{g}}$ & $0.814 \pm 0.031^{\mathrm{e}}$ \\
CAY & - & - & - & $0.985 \pm 0.009^{\mathrm{h}}$ \\
\hline
\end{tabular}

${ }^{\mathrm{a}-\mathrm{h}}$ : Values with different superscript are significantly different, $P<0.05$. Each value is a result of three different experiments.

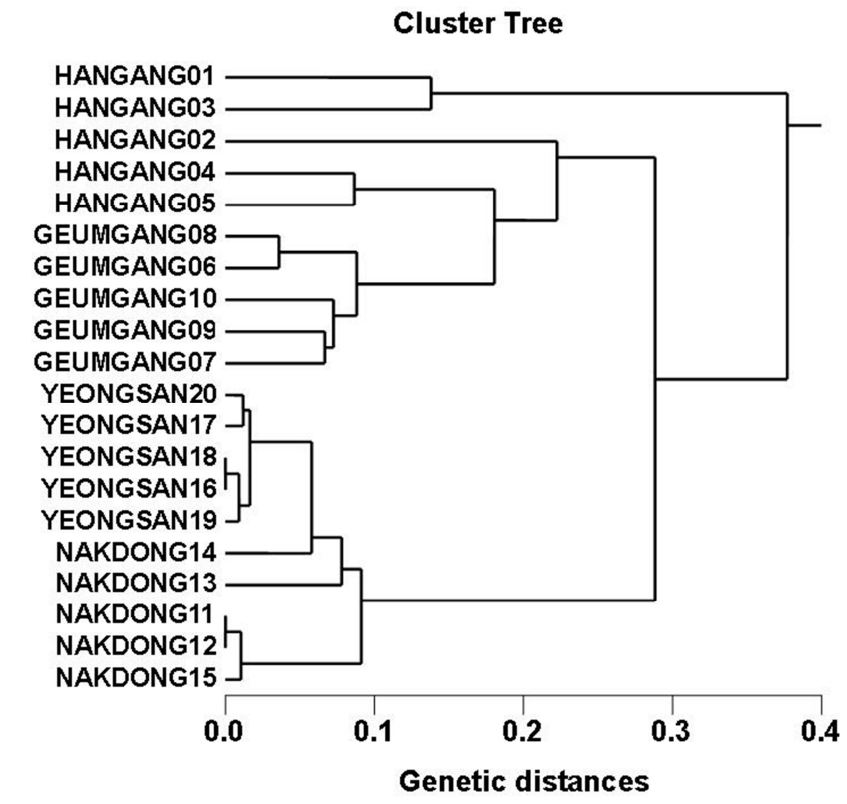

Fig. 2. Hierarchical dendrogram of genetic distances of individuals, obtained from four locations. The relatedness among different individuals of $\mathrm{CAH}$ population (HANGANG01 HANGANG05), CAG population (GEUMGANG06 GEUMGANG10), CAN population (NAKDONG11 NAKDONG15) and CAY population (YEONGSAN16 YEONGSAN20) of the Korean peninsula were generated according to the bandsharing values and similarity matrix.

individuals no.08 and no.09 from the CAG population (genetic distance $=0.088$ ). Relatively, individuals of CAY population were properly closely related to that of CAN population (genetic distance between two populations $<0.016$ ), as shown in the hierarchical dendrogram of genetic distances, as exposed in Fig. 2. PCR fragments revealed in the present study may be valuable as a DNA marker. The potential of amplified specific DNAs to identify diagnostic markers for species, locality and population identification in crucian carp (Yoon \& Park, 2001; Hong et al., 2007; Cheng et al., 2012) has also been well established. Crucian carp of four populations can be clearly distinguished by PCR-based approach. As mentioned above, this method can also be applied to other habitat of crucian carp and make technicallyconvenient the analysis of many samples. Using diverse oligonucleotides primers, this PCR analysis has been applied to identify polymorphic/specific markers particular to line, species, genus and geographical population, as well as genetic diversity/polymorphism in various species of organisms (Tassanakajon et al., 1998; McCormack et al., 2000; Yoon \& Kim 2004; Oh \& Yoon 2014; Yoon 2015). Preferentially, the habitat classification of genus Carassius is based on morphological variations in fin shape, body color, length and weight besides PCR analysis. In future, further research is necesarry for more profound population identification in crucian carp.

\section{ACKNOWLEDGEMENTS}

The authors are grateful to the referees who assisted with detailed rectification. Particular thanks also go to our laboratory collaborators, for their aids in mollusk sampling, DNA extraction/purification, gel electrophoresis, and their supports with PCR approaches. 


\section{REFERENCES}

Cheng L, Ye SW, Li ZJ (2012) Growth and population structure variations in crucian carp (Carassius auratus) between a macrophytic lake an algal lake at the middle part of Yangtze river basin. Acta Hydrobiol Sinica 36:957-964.

Choi KC, Jeon SL, Kim IS, Son YM (2002) Coloured Illustrations of the Freshwater Fishes of Korea. Hyangmunsa, pp. 29-30.

Hong SK, Jung JW, Koo HY, Kim W (2007) Development of species-specific molecular marker as a tool for discrimination between crucian carp gengorobuna (Carassius cuvieri) introduced from Japan and Korean native one (C. auratus). Korean J Limnol 40:143-148.

Jeffreys AJ, Morton DB (1987) DNA fingerprints of dogs and cats. Anim Genet 18:1-15.

Jo HB, Jang MH, Jeong KS, Do Y, Joo GJ, Yoon JD (2011) Long-term changes in fish community and the impact of exotic fish, between the Nakdong River and Upo Wetlands. J Ecol Field Biol 34: 59-68.

Johnston IA, Maitland B (1980) Temperature acclimation in crucian carp, Carassius carassius L., morphometric analyses of muscle fibre ultrastructure. J Fish Biol 17:113-125.

Kim IS, Kang EJ (1993) Coloured Fishes of Korea. Academy Book, pp. 136-137.

Kim SS (2015) The biochemical characteristics of heat shock factors (HSFs) from Carassius auratus. Dissertation of doctor, Pusan National University. pp. 1- 97.

McCormack GC, Powell R, Keegan B (2000) Comparative analysis of two populations of the brittle star Amphiura filiformis (Echinodermata: Ophiuroidae) with different life history strategies using RAPD markers. Mar Biotechnol 2:100-106.

Oh H, Yoon JM (2014) Genetic distances of three mollusk species investigated by PCR analysis. Dev Reprod 18:43-49.

Panicz R, Hofsoe P, Sadowski J, Mysłowski B, Polgesek M (2011) Morphometric and molecular characterization of Cyprinus carpio 3 Carassius auratus hybrids. Aquacult Internatioal. DOI 10.1007/s10499-012-9577-6.

Song YJ, Yoon JM (2013) Genetic differences of three Pollicipes mitella populations identified by PCR analysis. Dev Reprod 17: 199-205.

Takada M, Tachihara K, Kon T, Yamamoto G, Iguchi K, Miya M, Nishida M (2010) Biogeography and evolution of the Carassius auratus - complex in East Asia. BMC Evol Biol 10:7.

Tassanakajon A, Pongsomboon S, Jarayabhand P, Klinbunga S, Boonsaeng V (1998) Genetic structure in wild populations of black tiger shrimp (Penaeus monodon) using randomly amplified polymorphic DNA analysis. J Mar Biotechnol 6:249-254.

Yoke-Kqueen C, Radu S (2006) Random amplified polymorphic DNA analysis of genetically modified organisms. J Biotechnol 127:161-166.

Yoon JM (2015) Geographical variations and genetic distances of three Saxidomus purpuratus populations ascertained by PCR analysis. Dev Reprod 19:259-264.

Yoon JM, Kim JY (2004) Genetic differences within and between populations of Korean catfish ( $S$. asotus) and bullhead (P. fulvidraco) analysed by RAPD-PCR. AsianAust J Anim Sci 17:1053-1061.

Yoon JM, Park HY (2001) Genetic similarity and variation in the cultured and wild crucian carp (Carassius carassius) estimated with random amplified polymorphic DNA. J Anim Sci 15:470-476.

Yoon JM, Park SY (2006) Genetic comparison between crucian carp (Carassius auratus Linnaeus) and crucian carp (C. cuvieri Temminck and Schlegel). J Anim Sci \& Technol 48:637-650. 